\title{
COMPARISON OF POST-OPERATIVE ANALGESIC EFFICACY OF CAUDAL BLOCK VERSUS DORSAL PENILE NERVE BLOCK WITH BUPIVACAINE AND TRAMADOL FOR CIRCUMCISION IN CHILDREN
}

\author{
Rupal Kapadia1, Palakben Parikh², Ajay G. Prajapati³, Bhargav Trivedi' ${ }^{4}$ Nishita K. Mistry5
}

${ }_{1}^{1}$ Assistant Professor, Department of Anaesthesiology, NHL Medical College, Ahmedabad, Gujarat, India. ${ }^{2}$ Assistant Professor, Department of Anaesthesiology, NHL Medical College, Ahmedabad, Gujarat, India. 32nd Year Resident, Department of Anaesthesiology, NHL Medical College, Ahmedabad, Gujarat, India. 43rd Year Resident, Department of Anaesthesiology, NHL Medical College, Ahmedabad, Gujarat, India. ${ }^{52^{\text {nd }}}$ Year Resident, Department of Anaesthesiology, NHL Medical College, Ahmedabad, Gujarat, India. ABSTRACT

\section{BACKGROUND}

Circumcision is a painful intervention, frequently performed in paediatric surgery. We aim to compare the effects of penile block versus caudal block using bupivacaine with tramadol for circumcision to evaluate post-operative analgesia.

\section{MATERIALS AND METHODS}

This randomised controlled trial study was conducted on 60 healthy boys aged 1 - 7 years of American Society of Anaesthesiologist (ASA) class-1, scheduled for circumcision under general anaesthesia. The patients were randomly divided into two equal groups: Group P (penile block, $0.25 \%$ bupivacaine with tramadol $1 \mathrm{mg} / \mathrm{kg}, 0.5 \mathrm{~mL} / \mathrm{kg}, \mathrm{n}=30$ ) and Group C (caudal block, $0.25 \%$ bupivacaine with tramadol $1 \mathrm{mg} / \mathrm{kg}, 0.5 \mathrm{mg} / \mathrm{kg}, \mathrm{n}=30$ ). Post-operative pain is evaluated by the FLACC pain score and time to first rescue analgesic request as well as total doses of analgesic requirements were recorded.

\section{RESULTS}

The mean duration of analgesia was 22 +/- 4.45 hrs. in Group P, while in Group C it was $11+/-2.75$ hrs. (p= 0.0001). No significant difference was observed in incidence of haemodynamic changes or no side effect observed. Total analgesic requirement was also significantly low in Group P than Group C.

\section{CONCLUSION}

DPNB (bupivacaine with tramadol) for circumcision provides longer post-operative analgesia than caudal (bupivacaine with tramadol) without significant increase in rate of adverse effect.

\section{KEY WORDS}

Post-Operative Analgesia, Circumcision, DPNB, Caudal Block, Tramadol.

HOW TO CITE THIS ARTICLE: Kapadia R, Parikh P, Prajapati AG, et al. Comparison of post-operative analgesic efficacy of caudal block versus dorsal penile nerve block with bupivacaine and tramadol for circumcision in children. J. Evolution Med. Dent. Sci. 2018;7(42):4483-4486, DOI: $10.14260 /$ jemds/2018/1000

\section{BACKGROUND}

Pain relief after surgery continues to be a major medical challenge despite a significant improvement over the last decade in our understanding of acute pain mechanism. ${ }^{1}$ Although, pain is a predictable part of the post-operative experience, inadequate management of pain is common and have profound implications. ${ }^{2}$

The greatest advance in paediatric pain medicine is the recognition that untreated pain is a significant cause of morbidity and mortality after surgical trauma. ${ }^{3}$ Accurate assessment of pain in different age groups and effective treatment of post-operative pain is constantly refined with newer drugs being used alone or in combination with other drugs continues to be explored.

'Financial or Other Competing Interest': None.

Submission 04-09-2018, Peer Review 28-09-2018,

Acceptance 04-10-2018, Published 15-10-2018.

Corresponding Author:

Palakben Parikh,

B/503, Hari Heights,

Kudasan,

Gandhinagar-382421,

Gujarat, India.

E-mail: dr.palak.parikh@gmail.com

DOI: $10.14260 /$ jemds/2018/1000 parents as well as the treating doctor, hastens ambulation and quick discharge of patients.

Circumcision is the most common surgical procedure carried out in young male patients globally. ${ }^{(4,5)}$ It is generally performed under general anaesthesia in order to eliminate fear and anxiety.

Regional anaesthesia like caudal block and dorsal penile nerve block in combination with general anaesthesia is frequently used for children undergoing surgical procedures. Advantages of the technique are a smoother intra-operative course and decreased requirement of general anaesthesia, often leading to faster and smoother wakeup, decreased stress response and excellent pain relief in immediate postoperative period.

Different adjuvants have been added in regional nerve blocks to prolong the post-operative analgesia like clonidine, dexamethasone ${ }^{6}$, morphine etc. Tramadol have been used as an adjuvant in axillary brachial plexus nerve block, ${ }^{7}$ caudal anaesthesia $(8,9)$ and also in dorsal penile nerve block ${ }^{10}$ to extend the duration of post-operative analgesia.

In this study our aim is to compare post-operative analgesia, sedation status and complication between caudal block and DPNB with bupivacaine and tramadol in elective circumcision cases. 


\section{MATERIALS AND METHODS}

After obtaining parental written consent, a randomised controlled trial study was conducted on 60 ASA grade- 1 male children aged 1 - 7 years, scheduled for elective circumcision. The patients were randomly divided into two equal groups: Group P (penile block, $0.25 \%$ bupivacaine with tramadol $1 \mathrm{mg} / \mathrm{kg}, 0.5 \mathrm{~mL} / \mathrm{kg}, \mathrm{n}=30$ ) and Group C (Caudal block, 0.25\% bupivacaine with tramadol $1 \mathrm{mg} / \mathrm{kg}, 0.5 \mathrm{mg} / \mathrm{kg}, \mathrm{n}=30$ ) according to computer generated numbers. Post-operative pain is evaluated by the FLACC pain score and time to first rescue analgesic request as well as total doses of analgesic requirements were recorded.

Children with a history of pre-existing neurological or spinal disease, allergic reaction to local anaesthetics, bleeding diathesis, infection at injection site or parent's refusal were excluded from the study.

\section{Procedure}

Pre-operatively, patients were randomised into two groups. Group P $(\mathrm{n}=30)$ included patients who received penile block and Group C $(n=30)$ included patients who received caudal block.

Children were monitored with an ECG, NIBP, and Pulse oximetry and then induction of general anaesthesia was performed with a face mask using $8 \%$ sevoflurane in $100 \%$ 02. IV line secured. After induction appropriate size of laryngeal mask airway was placed according to children's age and weight without muscle relaxant. Inj. Atropine Sulphate according to patient's weight was given intravenously. Anaesthesia was maintained with $\mathrm{O}_{2}$, Nitrous Oxide and $1 \%$ of Sevoflurane.

After induction Group P (penile block) ( $n=30)$ received DNPB in supine position with $0.25 \%$ bupivacaine and Inj. tramadol $1 \mathrm{mg} / \mathrm{kg}$ with total volume of $0.5 \mathrm{~mL} / \mathrm{kg}$. After all aseptic precautions, a $30 \mathrm{~mm}$ long, 23G needle was inserted in the midline after gently pulling down the base of penis by the index finger and directed below the symphysis pubis through the Scarpa's fascia and into the subpubic space till give in feeling is appreciated. After a negative aspiration for blood, $25 \%$ of the calculated volume of drug is injected. The needle was withdrawn by $1-2 \mathrm{~mm}$ and redirected to $10: 00$ o'clock and 2:00 o'clock position and $25 \%$ of calculated volume of drug was injected on either side of midline to block the two dorsal nerves. An additional puncture was made on raphe line at the borderline between the penis and scrotum and the remaining $25 \%$ of the calculated drug volume was injected to alleviate possible pain arising from the skin innervated by the perineal nerves.

Group C (Caudal block) ( $n=30$ ) received caudal epidural block using $22 \mathrm{G}$ needle in lateral decubitus position. The needle was inserted into the caudal epidural space through sacral hiatus with loss of resistance technique and Inj. bupivacaine $0.25 \%$ and tramadol $1 \mathrm{mg} / \mathrm{kg}$ with total volume of $0.5 \mathrm{~mL} / \mathrm{kg}$ injected into the caudal epidural space.

Skin incision was performed after 20 mins of block in each group. If heart rate or blood pressure increases by more than $20 \%$ of the baseline after skin incision, means the block is unsuccessful and patient needs to receive analgesics in the form of $1 \mathrm{mg} / \mathrm{kg}$ ketamine for pain relief intraoperative and this patient was excluded from the study.
After emergence from anaesthesia, patients were shifted to recovery room where they were observed for pain, sedation and side effect (Nausea, vomiting, agitation, bleeding, penile haematoma, urinary retention, motor block) at 0, 5 mins, 15 mins, 30 mins, 1 hour and then every 2 hourly for next 24 hours.

\section{Statistical Analysis}

The observations were analysed using Epi Info software. Unpaired t-test was applied for demographic data, haemodynamic parameters, onset and duration of sensory/motor blockade and duration of analgesia, Chisquare test was applied for age, sex and ASA grades. P value $<0.05$ was considered as significant. Raw data were entered into an MS Excel spreadsheet and analysed using standard statistical software SPSS $^{\circledR}$ statistical package version 18.0 (SPSS Inc., Chicago, IL, USA).

\section{RESULTS}

Post-operative pain was assessed and evaluated by the FLACC pain score. This is a behavioural score for scoring post-operative pain in young children composed of five categories: (F) Face, (L) Leg, (A) Activity, (C) Cry, (C) Consolability [Table 1]. If the degree of pain scores (0-10) was $>/=4$, Ibuprofen was given as rescue analgesic in dose of $10 \mathrm{mg} / \mathrm{kg}$ in repeated doses every six hours orally (with a maximum daily dose of $40 \mathrm{mg} / \mathrm{kg}$ ). The time of first analgesia, total analgesic requirement, any complication or side effect due to block or general anaesthesia were observed and recorded. For sedation, Ramsay sedation score (Table 2) was used.

The randomised controlled trial study included 60 ASA grade 1 young boys undergoing circumcision. One patient in Group P and two patients in Group C were excluded from the study because of unsuccessful blocks. The remaining 57 patients were divided into Group P $(n=29)$ and Group C $(n=28)$. There were no significant difference between the two groups with regard to age, weight, duration of surgery or duration of anaesthesia (Table 2 and 3).

On evaluation of FLACC pain score at different time interval (after surgery 0, 5, 15, 30 mins, 1, 2, 4, 6, 8, 10, 12, 18, 24 hours) in the two groups, a total of 8 out of 29 patients in Group P and 18 out of 28 patients in Group C received analgesia in the first 24 hours post-operatively and the difference between two groups was significant.

The rescue analgesic requirements were significantly higher in the caudal group than in the penile group. The average time to first analgesia was significantly shorter in Group C (caudal group) (11 \pm 2.75 hours) than in penile group $(22 \pm 4.45$ hours $)(\mathrm{p}<0.0001)$ and time for ambulation was significantly longer in caudal group $(6.95 \pm 3.22$ hours $)$ than penile group $(4.36 \pm 1.99$ hours $)$ ( $p<0.0006)$. There were no cardiovascular, respiratory or neurovascular complications recorded in either groups and also no patients developed nausea, vomiting or urinary retention. 


\begin{tabular}{|c|c|c|c|}
\hline \multirow{2}{*}{ Categories } & \multicolumn{3}{|c|}{ Scoring } \\
\hline & $\mathbf{0}$ & 1 & 2 \\
\hline Face & $\begin{array}{l}\text { No particular } \\
\text { expression or } \\
\text { smile }\end{array}$ & \begin{tabular}{|c|} 
Occasional \\
grimace or \\
frown, \\
withdrawn, \\
disinterested
\end{tabular} & $\begin{array}{c}\text { Frequent to } \\
\text { constant } \\
\text { quivering chin, } \\
\text { clenched jaw }\end{array}$ \\
\hline Legs & $\begin{array}{l}\text { Normal } \\
\text { position or } \\
\text { relaxed }\end{array}$ & $\begin{array}{c}\text { Uneasy, } \\
\text { restless, tense }\end{array}$ & $\begin{array}{l}\text { Kicking or legs } \\
\text { drawn up }\end{array}$ \\
\hline Activity & $\begin{array}{l}\text { Lying quietly, } \\
\text { normal } \\
\text { position, } \\
\text { moves easily }\end{array}$ & $\begin{array}{l}\text { Squirming, } \\
\text { shifting back } \\
\text { and forth, } \\
\text { tense }\end{array}$ & $\begin{array}{l}\text { Arched, rigid } \\
\text { or jerking }\end{array}$ \\
\hline Cry & $\begin{array}{c}\text { No cry (awake } \\
\text { or asleep) }\end{array}$ & $\begin{array}{l}\text { Moans or } \\
\text { whimpers, } \\
\text { occasional } \\
\text { complaint }\end{array}$ & $\begin{array}{c}\text { Crying } \\
\text { steadily, } \\
\text { screams or } \\
\text { sobs, frequent } \\
\text { complaints }\end{array}$ \\
\hline Consolability & $\begin{array}{l}\text { Content, } \\
\text { relaxed }\end{array}$ & $\begin{array}{c}\text { Reassured by } \\
\text { occasional } \\
\text { touching, } \\
\text { hugging or } \\
\text { being talked to, } \\
\text { distractible }\end{array}$ & $\begin{array}{c}\text { Difficult to } \\
\text { console or } \\
\text { comfort }\end{array}$ \\
\hline & Table 1. F & CC Pain Score & \\
\hline
\end{tabular}

\begin{tabular}{|c|c|}
\hline 1 & Fully awake and oriented \\
\hline 2 & Awake, sleepy \\
\hline 3 & Asleep, but easily awaken by verbal stimulation \\
\hline 4 & Asleep, but easily awaken by motor stimulation \\
\hline 5 & $\begin{array}{c}\text { Asleep and cannot be awaken by verbal or motor } \\
\text { stimulation }\end{array}$ \\
\hline \multicolumn{2}{|c|}{ Table 2. Ramsay Sedation Score } \\
\hline
\end{tabular}

\begin{tabular}{|c|c|c|c|}
\hline & Group P & Group C & P value \\
\hline Age (years) & $3.47 \pm 2.56$ & $3.67 \pm 2.16$ & 0.75 \\
\hline Weight (kg) & $12.82 \pm 2.87$ & $13.91 \pm 2.32$ & 0.12 \\
\hline $\begin{array}{c}\text { Duration of } \\
\text { surgery (min) }\end{array}$ & $40 \pm 5.3$ & $42 \pm 5.1$ & 0.15 \\
\hline $\begin{array}{c}\text { Duration of } \\
\text { analgesia } \\
\text { (hours) }\end{array}$ & $22 \pm 4.45$ & $11 \pm 2.75$ & 0.0001 \\
\hline $\begin{array}{c}\text { Table 3. Comparison of Groups according to Age, Weight, } \\
\text { Duration of Analgesia }\end{array}$ \\
\hline
\end{tabular}

\begin{tabular}{|c|c|c|c|}
\hline Variables & $\begin{array}{c}\text { Group P } \\
(\mathbf{n = 2 9 )}\end{array}$ & $\begin{array}{c}\text { Group C } \\
(\mathbf{n = 2 8})\end{array}$ & P value \\
\hline $\begin{array}{c}\text { No. of patients } \\
\text { received }\end{array}$ & $8 / 29$ & $18 / 28$ & 0.0001 \\
\hline $\begin{array}{c}\text { Time of first } \\
\text { analgesia (hours })\end{array}$ & $22 \pm 4.45$ & $11 \pm 2.75$ & 0.0001 \\
\hline $\begin{array}{c}\text { Total doses of rescue } \\
\text { analgesia (mg) }\end{array}$ & $126 \pm 22.69$ & $523.8 \pm 124.1$ & 0.0001 \\
\hline $\begin{array}{c}\text { Time to ambulation } \\
\text { (hours) }\end{array}$ & $4.36 \pm 1.99$ & $6.95 \pm 3.22$ & 0.0006 \\
\hline \multicolumn{3}{|c|}{ Table 4. Post-operative Analgesic Requirement } \\
\hline
\end{tabular}

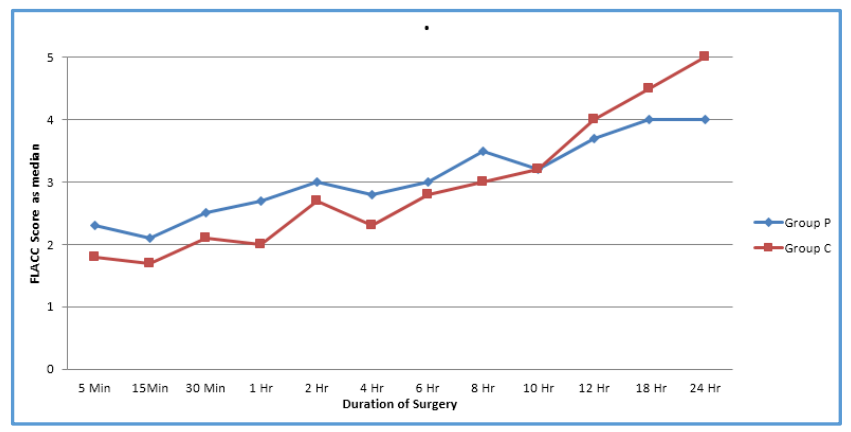

Figure 1. Comparison of Post-Operative Pain in Two Groups (FLACC Pain Score)

Comparison of Face, Legs, Activity, Cry, Consolability Score (FLACC) at different time intervals between the two groups. Data are presented as Median.

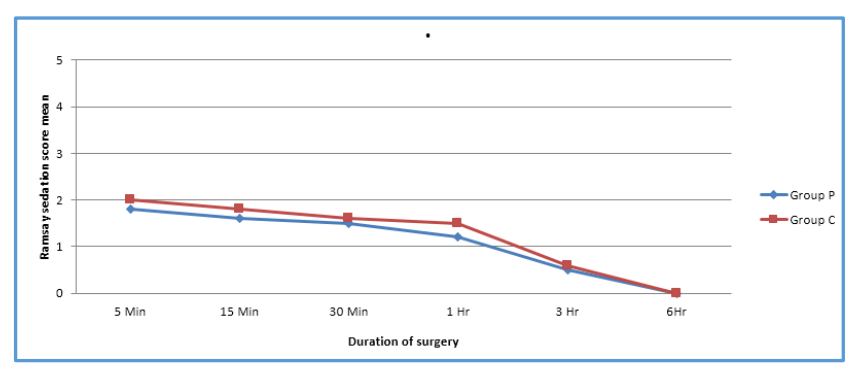

Figure 2. Comparison of Post-Operative Sedation in Two Groups

Fig. 2- Intergroup comparison of post-operative Ramsay sedation score versus time revealed that sedation score decreased significantly over time $(\mathrm{p}<0.001)$, but there was no significant difference between groups. Data are expressed as mean $+/$ - SD.

Ramsay sedation score was comparable in Group P and Group C. Comparing the score at all time intervals found no significant difference between two groups.

\section{DISCUSSION}

Circumcision is the most common surgical procedure carried out in the boys globally. $(4,5)$ Minimising complication and pain management are important issues and various researches were done on different anaesthetic and analgesic techniques. In our study, we have compared post-operative analgesia of caudal block versus DPNB with Bupivacaine and tramadol for circumcision.

Tramadol is a unique opioid with two modes of action for inhibition of pain, i.e. an opioid action mediated by $\mu$ receptor and a non-opioid action mediated by alpha-2 adrenergic and serotonergic activity.(11,12) The monoaminergic activity of tramadol inhibits the descending pain pathway, resulting in suppression of nociceptive transmission at the spinal level.(13) Many studies have characterised the effects of tramadol as an adjuvant to local anaesthetics in brachial plexus block, $(14,15,16)$ caudal epidural block $(17,18)$ and also in DPNB. ${ }^{10}$

We observed that duration of analgesia (FLACC < 4) without the need of rescue analgesia was significantly longer in Group P ( $22 \pm 4.4$ hours). Total dose of rescue analgesic was significantly higher in Group C (523 $\pm 124.1 \mathrm{mg})$. Total number of patients who required rescue analgesia were also significantly high in Group C (18/28). 
Our results are in agreement with Shrestha BR et al, who found that tramadol in injection with bupivacaine in DPNB can prolong the post-operative analgesia even up to 40 hours.[10]

Enas M Ashrey et al and Mohammad Alikhan et al found that FLACC pain score were significantly lower in Group $P$ compared to Group C ( $p<0.05)$. Also time to first need for analgesia was significantly $(p<0.05)$ lower in Group P compared to Group C. Total analgesic requirement was also significantly lower $(\mathrm{p}<0.05)$ in Group P compared to Group C. 19

Also, Kundra et al found that penile block provided better analgesia when compared with caudal epidural in children undergoing hypospadiasis repairs.[20]

In our study, time for ambulation is shorter in Group P ( $4.36+/-1.99$ hrs.) than in Group C (6.95 +/- 3.22). According to some studies, penile block has advantage over caudal block in terms of sensory and motor block to lower extremity.(19,21)

The pre-operative, intra-operative and post-operative haemodynamic variables between two groups were comparable and were not statistically significant and therapeutic intervention were not required.

There were no complication recorded such as nausea or vomiting and also no retention of urine. However, penile bleeding was seen in one case in each group. Other studies have also demonstrated that penile block as well as caudal block is associated with fewer side effects. $(19,22)$

\section{CONCLUSION}

Tramadol as an adjunct to Bupivacaine in DPNB compared to caudal epidural block for circumcision provides longer analgesic duration and causes reduced requirement for rescue analgesic in the post-operative period.

\section{REFERENCES}

[1] Australian and Newzealand College of Anaesthetics (ANZCA). Acute pain management: scientific evidence. http://www.Anzca.edu/su/publication/acute pain.htm [Accessed 24 July 2005].

[2] Apfelbaum JL, Chen C, Mehta SS, et al. Postoperative pain experience: result from a national survey suggest, postoperative pain continues to be undermanaged. Anaesthesia \& Analgesia 2003;97(2):534-40.

[3] Verghese ST, Hannallah RS. Acute pain management in children. Journal of Pain Research 2010;3:105-23.

[4] Al-Ghazo MA, Banihani KE. Circumcision revision in male children. Int Braz J Urol 2006;32(4):454-8.

[5] Lau JT. Penile block for pain relief after circumcision in children. A randomised, prospective trial. Am J Surg 1984;147(6):797-9.

[6] Shresth BR, Maharjan SK, Tabedar S. Supraclavicular brachial plexus block with and without dexamethasone - a comparative study. Kathmandu Univ Med J (KUMJ) 2003;1(3):158-60.

[7] Robaux S, Blunt C, Viel E, et al. Tramadol added to $1.5 \%$ mepivacaine for axillary brachial plexus block improves postoperative analgesia dose dependently. Department of Anaesthesiology and Critical Care Medicine. Anesth Analg 2004;98(4):1172-7.

[8] Batra YK, Prasad MK, Arya VK, et al. Comparison of caudal tramadol vs bupivacaine for postoperative analgesia in children under going hypospadias surgery. Department of anaesthesiology, post graduate institute of medical education and research, Chandigarh, India. Int $\mathrm{J}$ Clin Pharmacol Ther 1999;37(5):238-42.

[9] Senel AC, Akyol D. Dohman D, et al. Caudal bupivacaine - tramadol combination for postoperative analgesia in paediatric herniorraphy. Acta Anaesthesiologica Scandinavica 2001;45(6):786-9.

[10] Shrestha BR, Bista B. Tramadol along with local anaesthetics in the penile block for the children undergoing circumcision. Kathmandu University Medical Journal (KUMJ) 2005;3(1):26-9.

[11] Ground S, Sablotzki A. Clinical pharmacology of tramadol. Clinical Pharmacokinetics 2004;43(13):879923.

[12] Kayser V, Besson JM, Guilbaud G. Evidence of nonadrenergic component in the actinociceptive effect of the analgesic agent tramadol in an animal model of clinical pain, the arthritic rat. Eur J Pharmacol 1992;224(1):83-8.

[13] Arcioni R, Rocca DM, Romano S, et al. Ondansetron inhibits the analgesic effect of tramadol: a possible 5HT(3) spinal receptor involvement in acute pain in humans. Anesthesia and Analgesia 2002;94(6):1553-7.

[14] Nagpal V, Rana S, Singh J, et al. Comparative study of systemically and perineurally administered tramadol as an adjunt for supraclavicular brachial plexus block. Journal of Anaesthesiology Clinical Pharmacology 2015;31(2):191-5.

[15] Khosa AH, Asad N, Durvani H. Does the addition of tramadol to local anaesthetic mixture improve the quality of axillary brachial plexus block: a comparative study at the teaching hospital, Dera Ghazi Khan. Pakistan Journal of Medical and Health Sciences 2015;9(4):1120-3.

[16] Geze S, Ulusoy H, Ertuk E, et al. Comparison of anaesthetics mixtures with tramadol or fentanyl for axillary plexus block in orthopedic upper extremity surgery. European Journal of General Medicine 2012;9(2):118-23.

[17] Doda M Mukherjee S. Postoperative analgesia in children - comparative study between caudal bupivacaine and bupivacaine plus tramadol. Indian J Anaesth 2009;53(4):463-6.

[18] Solanki NM, Engineer SR, Jansari DB, et al. Comparison of caudal tramadol versus caudal fentanyl with bupivacaine for prolongation of postoperative analgesia in pediatric patients. Saudi J Anaesth 2016;10(2):154-60.

[19] Ashrey EM, Bosat BE. Single - injection penile block versus caudal in penile pediatric surgery. Ains-Shams Journal of Anaesthesiology 2014;7(3):428-33.

[20] Kundra P, Yuvaraj K, Agrawal K, et al. Surgical outcome in children undergoing hypospadias repair under caudal epidural vs penile block. Pediatric Anaeth 2012;22(7):707-12.

[21] Wilder RT, Goldschneider KR. Pain relief after outpatient surgery. In: Pain in Children. Humana Press 2008: p. 101-9.

[22] Seyedhajazi M, Azefarin R, Kazemi F, et al. Comparing caudal and penile nerve blockage using bupivacaine in hypospadias repair surgeries in children. Afr J Pediatric Surg 2011;8(3):294-7. 